\title{
Application of Cultural Elements of the Central Shaanxi Plain in Visual Communication Design of Yuanjiacun Village Scenic Spot
}

\author{
Xinping Zhao \\ School of Art \& Design \\ Xi'an University of Technology \\ Xi'an, China 710048
}

\author{
Yuyi Li \\ School of Art \& Design \\ Xi'an University of Technology \\ Xi'an, China 710048
}

\begin{abstract}
The visual communication design of scenic spots is one of the important factors affecting the development of tourism image and the formation of tourism brands. It is the external visual image of regional tourism culture industry. At the same time, with the impact of building a well-off society in an all-round way and the development strategy of the "Belt and Road", the economy and culture of the central Shaanxi plain have achieved tremendous development. Through the analysis of cultural elements of the central Shaanxi plain, and the characteristics of Yuanjiacun village scenic spot, this paper explores the influence and importance of the application of cultural elements of the central Shaanxi plain on the visual communication design of Yuanjiacun village scenic spot.
\end{abstract}

Keywords-Yuanjiacun village scenic spot; culture of the central Shaanxi plain; visual communication design; tourism development

\section{INTRODUCTION}

The pace of life is getting faster and faster. Leisure time is limited. Urban people are more likely to choose to go to the villages closer to the city to have the weekends. The air is fresh, the scenery is pleasant and the folk culture is rich in the countryside. Under the development of tourism and leisure villages, the following development models relying on the background of the village are gradually formed: "agritainment" that eat farmhouse meals and live in farmhouses; ecological villages with excellent natural environment; folk villages with typical folk culture; ancient villages with a large number of ancient buildings and farming experience villages. Due to the fierce competition, many folk villages with no special features and simple built of antique buildings have gradually declined. However, Yuanjiacun village gradually formed a unique brand benchmark by combining the local human environment, historical culture and regional characteristics of the central Shaanxi plain. And it prospers long.

\section{OVERVIEW OF YUANJIACUN VILLAGE}

Yuanjiacun Village is located in the north of Yanxia Town, Liquan County, Xianyang City, Shaanxi Province. It is located in Jiuzongshan Mountain, zhaoling mausoleum of Emperor Li Shimin. It is located in the hinterland of the central Shaanxi plain. China. It is surrounded by rich historical and cultural resources. Taking the opportunity of building a new socialist countryside, Yuanjiacun Village made an investment in establishing Ecosystem life Experience Village, Village History Museum, Baoning Temple in Tang dynasty and specialty snacks in the central Shaanxi plain in 2007, including the entertainment, sightseeing, leisure and catering. It becomes a well-known rural tourist destination. Yuanjiacun village has attracted a large number of tourists with its simple and natural style, unique folk custom culture of the central Shaanxi plain and rich rural tourism experience projects, and has been listed in the list of "National Scenic Tourism Famous Towns". The planning and design of Yuanjiacun village is based on the geographical location, taking folklore and leisure experience of the central Shaanxi plain as the wedge point. Therefore, in the tourism project and design style of Yuanjiacun village, the theme of antique rural courtyard of the central Shaanxi plain was created. Various cultural elements of the central Shaanxi plain were applied to the visual communication design of the scenic spot.

\section{TRADitional REgIONAL CULTURAL}

\section{CHARACTERISTICS OF THE CENTRAL SHAANXI PLAIN}

As the historical and cultural heritage passed down by Chinese civilization, the culture of the central Shaanxi plain not only has strong practicality, but also has high historical and cultural research value. It has various forms, which are full of various aspects of life, such as drama and entertainment, art and culture, home, lifestyle and clothing. There are strong customs in the central Shaanxi plain Among them, Shanxi opera is the representative of the regional cultural symbols in the central Shaanxi plain. The rough and simple expression is an important cultural label in the central Shaanxi plain. In addition, it has rich cultural heritage in the central Shaanxi plain. There are many kinds of folk traditional crafts and artworks. Traditional culture and art are also wonderful parts of traditional culture in the central Shaanxi plain, such as hand-cut, Fengxiang clay sculpture, wooden ladle, shadow puppets, and so on. The stone carvings and tile carvings such as the pegs, drumshaped bearing stones and the wall carvings in the central 
Shaanxi plain are exquisite and unique. These precious artworks and traditional handicraft workshops such as Tofu workshop, oil workshop, noodle workshop, blacksmith workshop, carpenter workshop, cotton pottery workshop, etc. show the local life and regional culture of the central Shaanxi plain in a dynamic form. In addition to living utensils, living habits, culture and art, rich historical and cultural heritage has also left a lot of historical stories and historical sites, which have a long history in the land of the central Shaanxi plain. At present, the existing traditional villages in the central Shaanxi plain still preserve a lot of cultural forms and are characterized by the diversity. Yuanjiacun village also applies these various characteristics and regional cultures of the central Shaanxi plain to the visual communication design of the scenic spot in a variety of forms, creating rich cultural atmosphere and strong regional uniqueness. Various cultural memory symbols have not disappeared with the advancement of social modernization. They are deeply rooted in the visual communication design of Yuanjiacun village scenic spot in the strong family and vivid form. It plays an important role in a certain range. Such visual communication designs can not only greatly enhance the interest of tourists, but also play an active role in promoting the historical and cultural inheritance of the central Shaanxi plain for thousands of years. It becomes a vivid business card of the central Shaanxi plain. The authors will mainly introduce some key cultural elements of the central Shaanxi plain applied in the visual communication design of Yuanjiacun village scenic spot.

\section{APPLICATION OF CULTURAL ELEMENTS OF THE} CENTRAL SHAANXI PLAIN IN THE VISUAL COMMUNICATION DESIGN OF YUANJIACUN VILlAgE SCENIC SPOT

\section{A. Architectural Culture}

People in the central Shaanxi plain use yellow as the main color of the building to form a unified architectural style. Instead of pursuing the richness of building materials, it is decorated with exquisite brick carvings. There are rich and exquisite carvings on the square tiles such as beautifully carved flower walls, shadow walls, doors and windows, pillar bases, etc. People of the central Shaanxi plain will focus on the residential architecture culture. And the most sophisticated in the visual design of Yuanjiacun village scenic spot is the gatehouse culture of the village. Here we mainly discuss the gatehouse culture in the architectural culture of Yuanjiacun village.

There are many people who can't help asking, what exactly is the gatehouse? And what role does it play in a building? The gatehouse is also the building on the city gate. The meaning of the "city gate building" in Shaanxi dialect is the same as that. The gatehouse is one of the traditional buildings in the central Shaanxi plain. The top of the gatehouse has overhang-roof building with double-sided brick carvings on the threshold. Also, there is an inscribed board. The gatehouse is the main ramp of a family, and it is also the facade. Visitors who have been there will be impressed by the gatehouse of Yuanjiacun village (as shown in "Fig. 1"). It is the facade and signboard of the entire Yuanjiacun village. The gatehouses of village are beautifully carved. The three characters of "Yuanjiacun" (袁家村) written by the former Chinese leader Hua Guofeng are engraved on the plaque. They are rich and elegant. They are also full of vicissitudes. This is also very compatible with the original tone of Yuanjiacun village.

Entering the gatehouse, people can go to the Yuanjiacun Food Pedestrian Street. The two-meter-wide brick-paved street relieves against the flow of the creeks built. On both sides of the street, there are erected large-scale houses with the characteristics of the central Shaanxi plain. There are many shops with distinctive features. The signboard of each store in Yuanjiacun Food Pedestrian Street has different wooden plaques and different quaint styles. The signboards hang in the center of the storehouse under the roof of the residential buildings. In addition to the eaves of the two corners of the rounded wood, there have two pillars on both sides of the gates. With the high gatehouses in Yuanjiacun village that must pass through, they echo each other, forming a distinct design system. The front doors of the shops in Food Street are based on the design of the gatehouses in the village. It is simplified, and retains the characteristics, and allows people to enter the Yuanjiacun village scenic spot to instantly feel the style of the central Shaanxi plain.

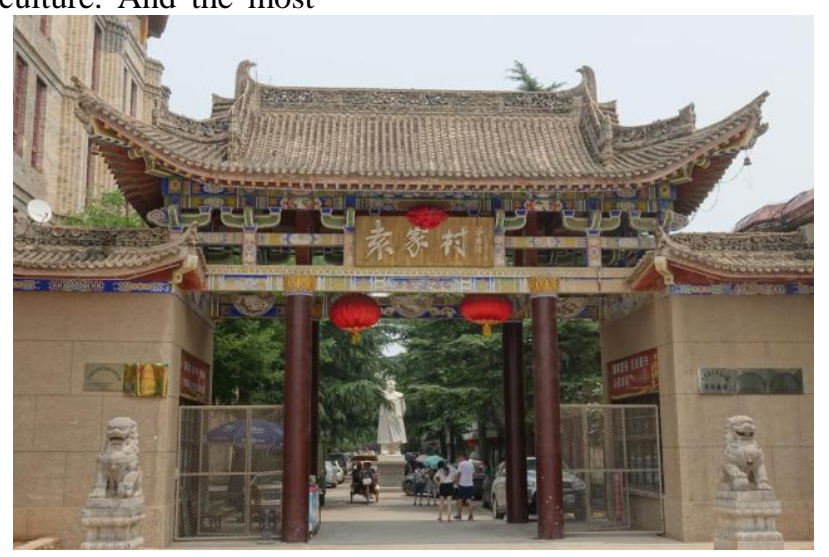

Fig. 1. Gatehouse in Yuanjiacun village. 


\section{B. Stone Carving and Brick Carving Culture}

The stone carving and brick carving culture in the central Shaanxi plain has a long history of development. The sculpture crafts and themes of the brick carvings are the embodiment and artistic expression of the characteristic style of the central Shaanxi plain. They also reflect the traditional and philosophical thinking and aesthetic thoughts of the central Shaanxi plain. Here, the authors mainly introduce the hitching posts, drum-shaped bearing stones and brick carvings that are frequently used in the visual design of Yuanjiacun village scenic spot.

The hitching posts are known as the representative of the stone carving culture in the central Shaanxi plain, and are known as the "ornamental columns of the family". The hitching post was originally a stone pillar used by the large and wealthy households in the past, which has both practical use and displays its status. The hitching post is set up on both sides of the building's entry and is a part of traditional dwellings in the central Shaanxi plain. It has the multiple meanings of decorative architecture, the noble status of the owner, and protecting the house from the evil spirits. According to the investigation, the hitching posts are mainly made of whole pieces of ash and black blue stone. They are strong and wearable. They can be stored in large quantities so far. It is generally about two meters high. Viewing the styling, the hitching posts can be divided into pile heads, pile necks, piles and roots from top to bottom. The pile head is the most important part of the whole hitching posts. And the sculpture is exquisite. The round carving technique is generally used, and the styles are rich and colorful. They can be divided into four types: spherical shapes (Mani beads, peach, melon, etc.), animal shapes (lion, monkey, etc.), character type and combination type of character and animal (person, lion, monkey, eagle, horse, etc.). The neck is the joint between the pile head and the pile body. The shapes are mostly the drum, xumizuo, the tiebeam, etc. and other shapes. Some auspicious patterns such as flowers, eight treasures, brocade, Bogu, etc. are embossed as the decoration. The pile body is mostly surrounded by four-corner or octagonal stone pillars. These pillars are generally engraved with regular transverse embossing. The pile root is buried in the ground for about one meter. The stone sculptures of the hitching posts not only reflect the life and cultural thoughts of people in the central Shaanxi plain, but also the continuous development of people's aesthetic consciousness. Therefore, the hitching posts will be indispensable in the local cultural landscape and visual design of the central Shaanxi plain in the present and future. In the Yuanjiacun scenic area, the application of the elements of the hitching posts can be seen everywhere.

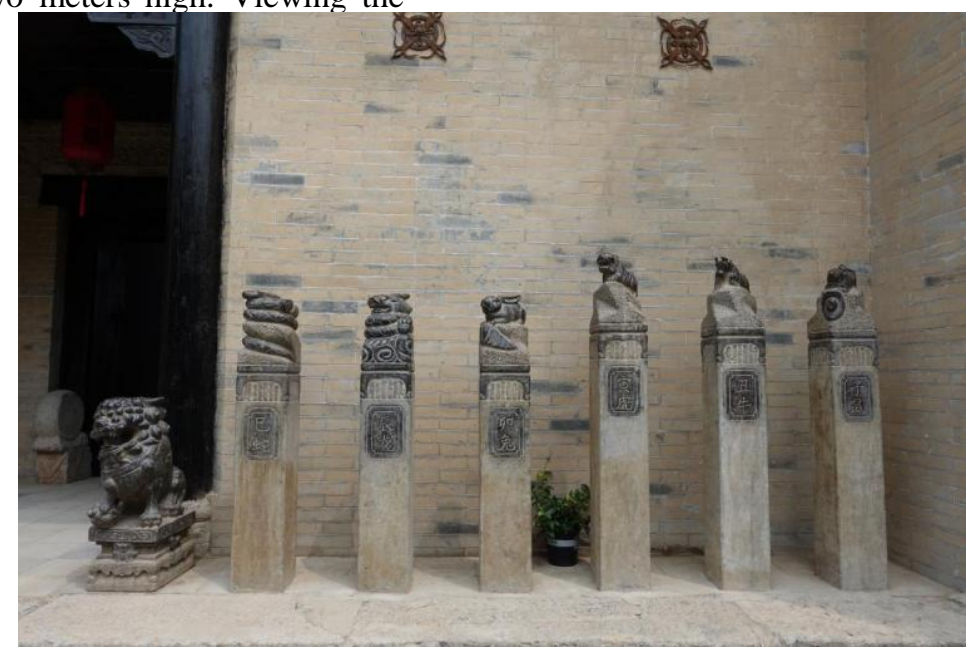

Fig. 2. The hitching posts in Yuanjiacun village scenic area.

The drum-shaped bearing stone is a common stone carving in the dwellings of the central Shaanxi plain. It is not unique in the nationwide. The name is not the same everywhere, such as the door drum, the stone mirror and many other names. However, they are one kind of door sleeper stones, which are placed in pairs on both sides of the door of the dwelling. It not only has the function of bearing the weight and moisture, but also has the features of showing family status and decorating the door. Also, it expresses the hope of the owner that the children and grandchildren are prosperous, the family business is prosperous, and the road is smooth. The drum-shaped bearing stone in the central Shaanxi plain is similar in structure to that of other areas. The basic structure consists of five layers: the base, the drum base, the drum barrel, the drum body and the drum head. The outstanding point is that the drum-shaped bearing stone of the central Shaanxi plain adopts a partially symmetrical structure with a tightening bottom. The outer edge of the base and the drum seat is about a fifth of the distance from the drum body to the inside of the door, which makes the drum-shaped bearing stone present an unbalanced situation in the vision and adds the rolling and layering of drumshaped bearing stone. It reflects the artistic expression that there is uplift in the depression, and there is the depression in the uplift. Finally, in the decoration, the carving styles of the drum-shaped bearing stone of the central Shaanxi plain are rich and varied, including the animals, characters and plants. Most of them are dominated by large-scale blocks, avoiding the trivial and messy feelings. For example, in the central Shaanxi plain, there are many drum-shaped bearing stones 
with small stone lions carving on it. From the perspective of their demeanor, they do not focus on the singular and majestic look of the lion. These lions show the naive feelings. People can see the modeling characteristics that the coarse is in the details. The head depictions are fine but follow the principle of "focusing on the circumstances and ignoring the decoration".

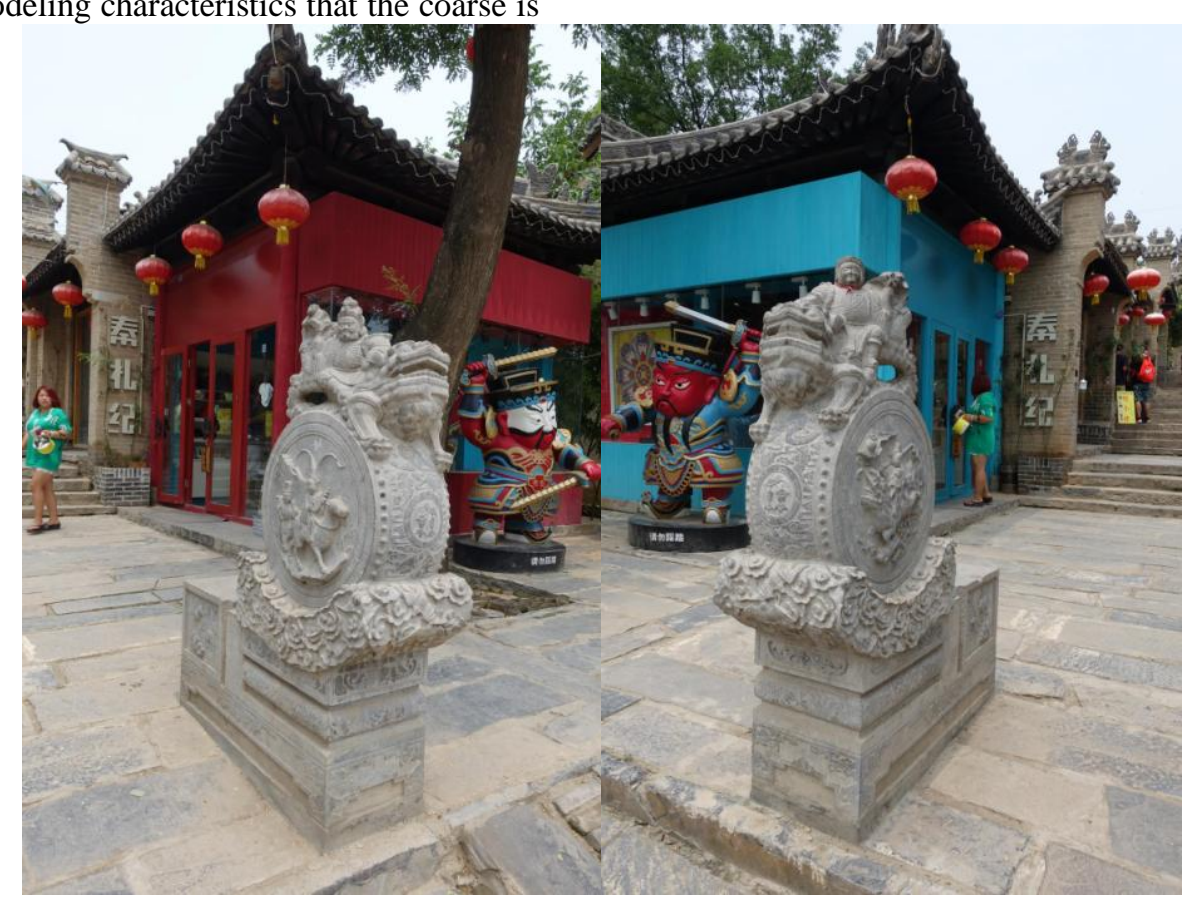

Fig. 3. The drum-shaped bearing stone next to Qin Qiong's tomb in Yuanjiacun Village.

The brick carving process in the central Shaanxi plain is exquisite, and the composition is full and simple. The carving technique is a combination of hard stems and soft terms, reflecting the simple and delicate style of the northwest. The theme of brick carvings in folk houses of the central Shaanxi plain is mostly auspicious. Through changing the density, size, concave-convex and rights and wrongs of the shape, the whole wall is very solid, adding a flexible and varied visual effect to the rigid wall and expressing strong emotion. The screen wall is the crowning brush of the brick carvings in the dwellings of the central Shaanxi plain. The beautifully carved places are the niches and the four corners. The engravings are the animals and plants that can represent the master's sentiments and aesthetics. The brick carving art in the central Shaanxi plain has a long history. As early as the Qin dynasty, there were dragon-shaped hollow bricks with exquisite carvings. The exquisite artistic level of brick carving in the central Shaanxi plain reflects the attitude of people of the central Shaanxi plain towards life and the beauty. Brick carvings have also been frequently applied to the wall decoration in Yuanjiacun village scenic area.

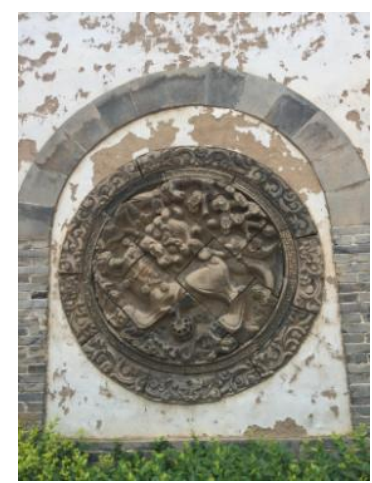

Fig. 4. Brick carving on the wall of Yuanjiacun scenic spot.

\section{Traditional Crafts}

There are many kinds of traditional handicraft elements appearing in the visual communication design of Yuanjiacun Scenic Area, such as paper-cut, clay sculpture, embroidery, wooden ladle, shadow puppets, MaiXuan pyrograph, wheat strawing, wooden painting, gold lacquer, etc. Here the authors focus on the facial makeup of wooden ladle in the logo design of Yuanjiacun village. 


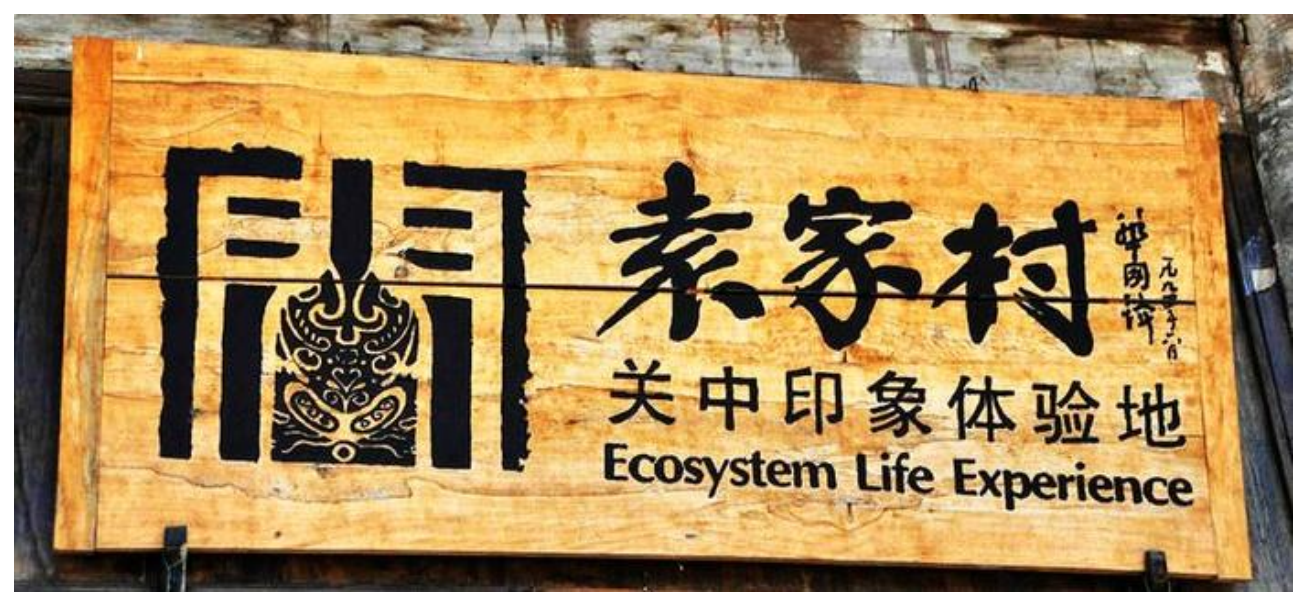

Fig. 5. The plaque of Yuanjiacun village scenic area.

The wooden ladle is a unique handicraft in the central Shaanxi plain. It has been evolved and improved by the Chinese folk Shehuo facial makeup. The most distinctive feature is that it uses wooden ladle as the canvas (the wooden ladle is originally a daily tool of the local Han ancestors). The craftsman with superb painting techniques outlines the western style of the red and green. With the ancient forms, exaggerated patterns, rich colors and amazing imagination, people can feel the changeable paintings. It fully demonstrates the skills and tastes of the working people in the central Shaanxi plain. The work of the facial makeup of wooden ladle is taken from the facial features of the characters in the "The Legend of Deification", "Romance of the Three Kingdoms", folklore and local operas. It has many meanings such as protecting people from evil spirits and ghosts, and bringing people the blessings. The Shehuo facial makeup expresses the characters such as loyalty, traitor, goodness and evil in color. For example, red represents loyalty, white represents fraudulent, black represents righteousness, and so on. The facial makeup of Shehuo wooden ladle carries forward the long-standing culture of the Chinese nation and exudes the charm of the culture of Zhou dynasty and Qin dynasty. Yuanjiacun village also applied the facial makeup of wooden ladle of the cultural symbols with the characteristics of the central Shaanxi plain to the logo design. In the figure "門", there is a wooden ladle pattern that reproduces the traditional craftsmanship of folks of the central Shaanxi plain. It reflects the unique folk culture and the beauty of detail in Yuanjiacun village- Ecosystem life experience. It will bring people an intuitive and rich visual impression.

\section{CONCLUSION}

Today, the economy and culture are flourishing. We must realize that we live in a branded world. Folk villages are an important way to show and protect national culture. The construction of folk villages is an inevitable trend in economic and cultural development. Taking history culture, folk culture, natural environment and so on as the core, we must understand consumers, and attract and retain consumers with the unique brands. We can differentiate the image of folk villages with local brand features, and break the pattern of no difference and no characteristics in folk villages. By analyzing the application of cultural elements in the visual communication design of Yuanjiacun scenic spot, Yuanjiacun's development can be smoother. Under the basic premise of protecting and inheriting national cultural heritage, we can better display invaluable culture of the central Shaanxi plain.

\section{REFERENCES}

[1] Sui Lina. Research on Intangible Cultural Heritage in the central Shaanxi plain: from the Perspective of Cultural Ecology. Nankai University Press, 2014.

[2] Chen Hua. Study on the Aesthetics of Traditional Chinese Folk hitching post Stone Carvings in the central Shaanxi plain[D]. PhDD Thesis of Northwest University, 2014.

[3] Zhou Jianming. Traditional Chinese Villages - Protection and Development. China Building Industry Press, 2014.

[4] Wang Jun. Research on the development of Xi'an historical and cultural tourism in the ancient capital [M]. Xi'an Map Press.

[5] Zhou Zuoming. New Theory of Chinese Folklore Tourism, Tourism Education Press, 2011 